\title{
CHARACTERISTICS OF THE RESPIRATORY MUSCLE STRENGTH OF WOMEN AND MEN AT DIFFERENT TRAINING LEVELS
}

\author{
ANDRZEJ KLUSIEWICZ, ŁUKASZ ZUBIK, BARBARA DŁUGOŁĘCKA, MAŁGORZATA CHARMAS \\ Józef Piłsudski University of Physical Education in Warsaw, \\ Faculty of Physical Education and Sport in Biała Podlaska, \\ Department of Physiology and Biochemistry

\begin{abstract}
Mailing address: Andrzej Klusiewicz, Faculty of Physical Education and Sport, Department of Physiology e-mail: andrzej.klusiewicz@insp.waw.pl
\end{abstract} \\ and Biochemistry, 2 Akademicka Street, 21-500 Biała Podlaska, tel.: +48 83 3428726, fax: +48 833428800 ,
}

\begin{abstract}
Introduction. The objective of the study was to determine the maximal inspiratory mouth pressure (PImax) of highly trained male and female athletes competing in endurance sports and of non-training students of both sexes. Analysis was conducted of the dependence of PImax levels on somatic indices and training experience. The reproducibility of the method for measuring PImax index was determined. Material and methods. The study examined a total of 234 training and non-training individuals (78 women and $156 \mathrm{men}$ ). The test subjects were measured for PImax, as well as inspiratory time, active time, passive time and diaphragm relaxation time. A group of 59 women and men (training and non-training) were tested a second time within 5-7 days of the first test to determine the reproducibility of the PImax measurements. Results and conclusion. The measurements were found to be highly reproducible (between the first and second tests no statistically significant differences were found, all spirometric indices included in the study were shown to demonstrate a significant correlation, and total error for all of the analyzed indexes was between 11.1 and 24.3\%). Reference ranges for PImax were determined for women and men at different training levels. PImax was shown to have a positive dependence on somatic indices characterizing male and female body mass.
\end{abstract}

Key words: maximal inspiratory mouth pressure (PImax), training and non-training individuals (women, men), endurance training

\section{Introduction}

One of the most commonly used methods for diagnosing the functional capacity of the respiratory muscles is to measure maximal inspiratory mouth pressure (PImax) in the oral cavity [1]. This is a simple, reproducible and non-invasive method for assessing the strength of respiratory muscles, one that is generally used to diagnose lung diseases in specialized clinics [2, 3, $4,5]$. This parameter also corresponds to the ability to generate force through the combined, maximal effort of the respiratory muscles during a short, almost static contraction throughout which the air flow through the air passages remains almost entirely restricted. It bears mentioning that published PImax values vary greatly depending on such factors as the study population, the measurement technique and the test subjects' motivation [2]. For this reason, it is suggested that each laboratory work out its own frame of reference.

The question that interested the authors was to assess the influence of endurance training on the functioning of respiratory muscles. PImax measurements were taken of representative groups of female and male athletes with high levels of fitness and many years of training, and the results obtained were compared to values obtained for young, non-training but physically active students from the University of Physical Education. The objective of the study was to determine the PImax value of highly trained athletes competing in endurance sports and of non-training students, as well as to investigate fundamental relationships between the value of this index and somatic indices and training experience. An important aspect of the study was to determine the reproducibility of the method for measuring PImax index.

\section{Material and methods}

Tests were conducted on 78 women (45 training and 33 nontraining) and 156 men (80 training and 76 non-training), or a total of 234 people. The test subjects are characterized in table 1. The groups of non-training individuals consisted of healthy students at the University of Physical Education, while the training groups consisted of male and female athletes, ranging in category from junior to senior, and primarily participating in endurance sports: biathlon, kayaking, rowing, swimming and team sports. In the groups of non-training male and female students, 12 of the 109 subjects (11\%) smoked cigarettes. The test subjects had no previous experience in taking spirometric measurements, and immediately prior to the study they were briefed on the measurement procedure and study methodology. In a group of 59 women and men (training and non-training) the study was conducted a second time within 5-7 days under the same laboratory conditions and at the same time of day. The measurements were all taken by the same technician. 
Table 1. Characterization of male and female test subjects (mean \pm SD), total $n=234$

\begin{tabular}{|c|c|c|c|c|c|c|}
\hline Group & N & $\begin{array}{c}\text { Age } \\
\text { (years) }\end{array}$ & $\begin{array}{c}\text { Body height } \\
(\mathrm{cm})\end{array}$ & $\begin{array}{c}\text { Body mass } \\
(\mathrm{kg})\end{array}$ & $\begin{array}{c}\text { BMI } \\
\left(\mathrm{kg} / \mathrm{m}^{2}\right)\end{array}$ & $\begin{array}{c}\text { Training } \\
\text { experience } \\
\text { (years) }\end{array}$ \\
\hline $\begin{array}{c}\text { Non-training } \\
\text { female students }\end{array}$ & 33 & $21.8 \pm 1.5$ & $167 \pm 5$ & $59.5 \pm 7.3$ & $21.3 \pm 2.4$ & - \\
\hline $\begin{array}{c}\text { Female } \\
\text { athletes }\end{array}$ & 45 & $21.0 \pm 3.7$ & $172 \pm 8$ & $66.0 \pm 9.4$ & $22.2 \pm 2.0$ & $7.7 \pm 4.5$ \\
\hline $\begin{array}{c}\text { Non-training } \\
\text { male students }\end{array}$ & 76 & $22.3 \pm 1.9$ & $180 \pm 6$ & $77.1 \pm 9.9$ & $23.7 \pm 2.5$ & - \\
\hline $\begin{array}{c}\text { Male } \\
\text { athletes }\end{array}$ & 80 & $24.1 \pm 3.7$ & $184 \pm 8$ & $82.6 \pm 11.3$ & $24.3 \pm 2.4$ & $10.5 \pm 4.2$ \\
\hline
\end{tabular}

The subjects agreed to participate in the study, and the study program was approved by the Senate Ethics Committee for Scientific Research of the Józef Piłsudski University of Physical Education in Warsaw and the Research Ethics Committee of the Institute of Sport in Warsaw.

\section{Measurement of maximal inspiratory mouth pressure (PImax)}

PImax was measured based on a procedure that has already been described by other authors [2, 5, 6, 7]. A minimum of 10 and a maximum of 15 technically satisfactory inspirations are performed. The three highest measurements exhibiting no more than $5 \%$ variability are designated as the maximum. The initial positioning of the respiratory muscles was controlled by beginning each effort from residual volume (RV). All of the actions were performed from a standing position. The subjects were verbally encouraged to make a maximum effort, and they obtained feedback information on a monitor screen (visual feedback) concerning the inspiratory pressure of each attempt (fig. 1). The following were registered:

- active time (Tactive) - segment on the time axis between the point of intersection of the tangents indicated on the time axis and the intersection of the tangent and the axis on the rising portion of the graph),

- passive time (Tpassive) - segment on the time axis between the point of intersection of the tangents indicated on the time axis and the intersection of the tangent and the axis on the falling portion of the graph),

- inspiration time (Tin),

- respiratory muscle relaxation time ( $\mathrm{tD}$ ), defined as the time it takes for the pressure to fall from its highest value (PImax) to zero (PIo). Points PImax and PIo are calculated from the tangent to the middle segment (50-80\%) of the relaxation time curve [8].

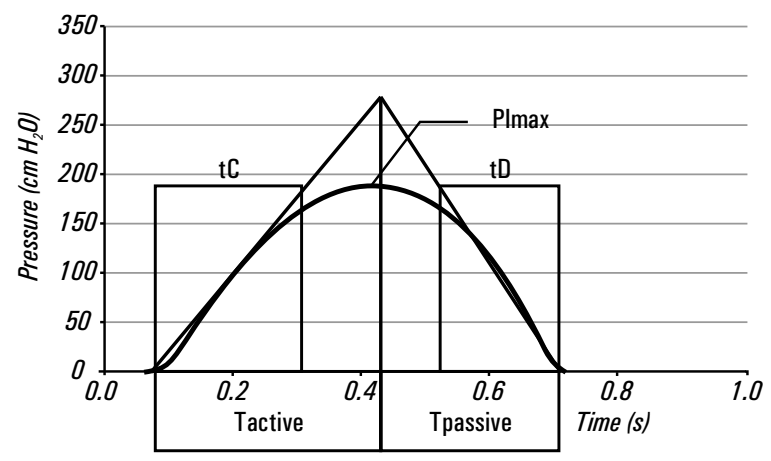

Figure 1. Curve indicating changes in inspiratory pressure during an vigorous inspiration with characteristic measuring points
The measurements were carried out using the electronic equipment supplied with the Lungtest 1000 computer software (MES, Krakow, Poland) capable of transmitting the pressure from the site of the measurement (the mouthpiece) to the pressure sensors.

\section{Anthropometric measurements}

Body height and mass were determined using conventional methods. Body composition (body fat and lean body mass) were only measured for non-training male and female students using bioimpedence analysis (BIA) with the aid of BC-418 MA analyzers produced by Tanita (Japan).

\section{Statistical calculations}

The results were subject to statistical analysis, calculating: the mean values of the examined characteristics, standard deviation (SD) and total error (TE).

In assessing whether the distribution of the examined variables conforms to normal distribution, the Shapiro-Wilk test was applied. The degree of dependence between the variables was assessed based on calculations of Pearson product-moment correlation coefficients. In cases where the distributions of the variables deviated significantly from normal distribution, Spearman's rank correlation coefficients were calculated. The significance of the differences between the means was assessed using Student's t-test (for dependent and independent samples). In con-ducting the statistical analysis, the value of $p<0.05$ was defined as significant.

Calculations and statistical analysis were conducted using the following computer programs: Statistica v. 8.0 (StatSoft) and Excel 2007 (Microsoft Office).

\section{Results}

No statistically significant differences were observed between the first and second measurements taken 5-7 days apart for: PImax, inspiration time, active time, passive time and diaphragm relaxation time, which shows that the method is reproducible (tab. 2). In all cases, analysis of the correlation coefficients for the aforementioned spirometric indices indicated statistically significant dependencies between the first and second test, along with relatively differentiated relative total error (between 11.1 and 24.3\%).

Table 2. Values of maximal inspiratory mouth pressure (PImax), inspiration time (Tin), active time (Tactive), passive time (Tpassive), diaphragm relaxation time (tD), correlation coefficient $(\mathrm{R})$, total error (TE) and relative total error (TE, \%) in studies repeated among women and men $(\mathrm{n}=59)$

\begin{tabular}{|l|c|c|c|c|c|}
\hline Variable/Test & Test 1 & Test 2 & R & TE & TE $(\%)$ \\
\hline PImax $\left(\mathrm{cm} \mathrm{H}_{2} \mathrm{O}\right)$ & $102 \pm 33$ & $104 \pm 30^{\mathrm{NS}}$ & $0.94^{*}$ & 11.3 & 11.1 \\
\hline Tin $(\mathrm{ms})$ & $599 \pm 159$ & $571 \pm 162^{\mathrm{NS}}$ & $0.77^{*}$ & 111 & 18.5 \\
\hline Tactive $(\mathrm{ms})$ & $260 \pm 72$ & $245 \pm 80^{\mathrm{NS}}$ & $0.67^{*}$ & 63 & 24.3 \\
\hline Tpassive (ms) & $215 \pm 75$ & $208 \pm 72^{\mathrm{NS}}$ & $0.83^{*}$ & 42 & 19.7 \\
\hline tD (ms) & $115 \pm 25$ & $111 \pm 21^{\mathrm{NS}}$ & $0.70^{*}$ & 19 & 16.1 \\
\hline
\end{tabular}

Ns - insignificant statistical differences between 1 and $2(p>0.05)$,

* - significance of the correlation coefficient $(\mathrm{p}<0.001)$.

The measurements made it possible, above all, to specify reference ranges for PImax, assuming an average range for the arithmetic mean of $\pm 1 / 2$ SD (tab. 3). The PImax values obtained for male and female athletes were significantly higher than corresponding values registered for non-training male and female students. 
Table 3. Value of maximal inspiratory mouth pressure (PImax) registered in test groups of non-training and training women and men (mean $\pm \mathrm{SD})$

\begin{tabular}{|c|c|c|c|c|c|}
\hline \multirow{2}{*}{ Group } & \multirow{N}{*}{$\mathrm{N}$} & \multicolumn{4}{|c|}{ PImax $\left(\mathrm{cm} \mathrm{H}_{2} \mathrm{O}\right)$} \\
\cline { 3 - 6 } & & Mean \pm SD & Low & Average & High \\
\hline $\begin{array}{c}\text { Non-training } \\
\text { female students }\end{array}$ & 33 & $72 \pm 18$ & $\leq 62$ & $63-81$ & $\geq 82$ \\
\hline $\begin{array}{c}\text { Female } \\
\text { athletes }\end{array}$ & 45 & $113 \pm 25^{*}$ & $\leq 99$ & $100-126$ & $\geq 127$ \\
\hline $\begin{array}{c}\text { Non-training } \\
\text { male students }\end{array}$ & 76 & $106 \pm 24$ & $\leq 93$ & $94-118$ & $\geq 119$ \\
\hline $\begin{array}{c}\text { Male } \\
\text { athletes }\end{array}$ & 80 & $141 \pm 29^{*}$ & $\leq 125$ & $126-156$ & $\geq 157$ \\
\hline
\end{tabular}

* - statistically significant difference $(\mathrm{p}<0.001)$ between non-training and training subjects, Student's t-test.

With regard to dependencies between PImax values and somatic indices, significant correlation indexes were noted among women (students) and between PImax and height $(\mathrm{r}=0.38)$, body mass $(\mathrm{r}=0.39)$ and lean body mass $(\mathrm{r}=0.46)$. However, in the group of men, PImax correlated significantly to body mass $(\mathrm{r}=0.32)$, BMI $(\mathrm{r}=0.39)$ (athletes) and lean body mass ( $\mathrm{r}=0.23$ ) (students), (tab. 4).

Table 4. Values of correlation coefficients between maximal inspiratory mouth pressure (PImax) and somatic indices and training experience registered for groups of non-training male and female students and male and female athletes

\begin{tabular}{|c|c|c|c|c|}
\hline & $\begin{array}{c}\text { Female } \\
\text { students } \\
(n=33)\end{array}$ & $\begin{array}{c}\text { Male } \\
\text { students } \\
(n=76)\end{array}$ & $\begin{array}{l}\text { Female } \\
\text { athletes } \\
(n=45)\end{array}$ & $\begin{array}{c}\text { Male } \\
\text { athletes } \\
(n=80)\end{array}$ \\
\hline & \multicolumn{4}{|c|}{ PImax $\left(\mathrm{cm} \mathrm{H}_{2} \mathrm{O}\right)$} \\
\hline Body height (cm) & $0.38^{*}$ & 0.05 & 0.10 & 0.09 \\
\hline Body mass (kg) & $0.39 *$ & 0.18 & -0.01 & $0.32^{*}$ \\
\hline BMI $\left(\mathrm{kg} / \mathrm{m}^{2}\right)$ & 0.24 & 0.19 & -0.14 & $0.39 *$ \\
\hline Body fat $(\mathrm{kg})$ & 0.27 & 0.08 & $\cdot$ & $\cdot$ \\
\hline Lean body mass $(\mathrm{kg})$ & $0.46^{*}$ & $0.23^{*}$ & - & - \\
\hline Training experience (years) & $\cdot$ & $\cdot$ & -0.05 & -0.09 \\
\hline
\end{tabular}

* - significance of correlation coefficients $\mathrm{p}<0.05$.

\section{Discussion}

One of the most significant problems involved in introducing a new measurement method into the laboratory is assessing its reproducibility. In the literature on the subject, there are not many studies on the reproducibility of non-invasive measurements of the functioning of respiratory muscles. Romer et al. [7] obtained high reproducibility for non-invasive measurements of maximal inspiratory pressure (MIP) and maximal expiratory pressure (MEP), expressed in terms of the agreement ratios ranged from 1.05 to 1.06 . Comparably high reproducibility for measurements of maximal inspiratory mouth pressure (PImax) and maximal expiratory mouth pressure (PEmax) were obtained by McConnell and Copestake [9], with reproducibility coefficients of 10.2 and $12.8 \%$, respectively. It should be emphasized that two factors exerted a large influence on the measurements: how skillfully the personnel conducted the test and how motivated the test subject was [10]. Tests conducted by the authors to evaluate the reproducibility of measurements of se- lected spirometric indices confirmed the reliability of the applied methodology. No statistically significant differences were found between the repeated measurements, and high values were noted for correlation coefficients between the first and second measurement. It bears mentioning that total error was at its highest for active time (24.3\%), and at its lowest for PImax (11.1\%). This is probably because the test subject has more of a chance to influence how this measurement is taken than to influence the value of maximal inspiratory mouth pressure itself, for which the differences between the mean values of the two measurements was $2 \%$. The relative total error values for the remaining indices (Tin, Tpassive and $\mathrm{tD}$ ), which greatly exceeded $10 \%$, confirm the relatively high variability of the values obtained from repeated spirometric measurements (tab. 2).

In studies devoted to mechanisms influencing respiratory muscle fatigue among patients, particular attention is paid to the diaphragm $[11,12]$. Thus, the Institute of Tuberculosis and Lung Diseases developed a computerized method for analyzing diaphragm relaxation time - an important aspect of patient diagnosis. During diaphragm relaxation time, the muscle returns to its initial length and tension. This phase plays a fundamental role in the perfusion of blood through the muscle. The mechanism responsible for slowing relaxation after fatigue has set in seems to be the reduced tempo of calcium influx into the sarcoplasmic reticulum and the distribution of the lateral bridges [12]. In the authors' own tests mentioned above, the diaphragm relaxation time was $115 \pm 25 \mathrm{~ms}$ for the first measurement and underwent an insignificant reduction of $3.5 \%$ for the second measurement. It is assumed that under normal conditions this time varies between 60 and $120 \mathrm{~ms}$ and grows longer proportionate to the degree of diaphragm muscle fatigue. Assessing the suitability of the measurement of diaphragm relaxation time for healthy individuals after intense physical exertion remains an open question.

The goal of the authors' own tests, apart from verifying the reproducibility of the method used to measure PImax, was to determine reference values for this index for persons of both sexes at different training levels (tab. 3). In conducting the tests, the characteristic in question was given in terms of three levels: low, average and high. For the average level, an arithmetic mean of \pm 0.5 SD was assumed. The collected data confirmed earlier observations [2], i.e. a significantly higher PImax value among athletes as compared to non-training individuals. In other studies, Fuso et al. [6] indicate that measuring respiratory muscle strength from functional residual capacity (PImaxFRC) is more diagnostic in distinguishing non-training individuals from athletes than the most common method: measuring from the initial position of respiratory muscles from residual volume (PImaxRV). Adding gender to the equation, studies by Hautmanna et al. [10] involving large groups of women and men (total $n=504$ ) between the ages of 18 and 82 yielded a mean PImax value for women that was $25 \%$ lower than for men $(\mathrm{p}<0.001)[10]$.

The PImax value for male and female students obtained from the authors' tests was around 20\% lower (tab. 5) as compared to data from the literature for non-training individuals $[10,13,14]$. For athletes, the authors provide more differentiated values, from 104 to $130 \mathrm{~cm} \mathrm{H}_{2} \mathrm{O}$ among female athletes [2, 15] and from 100 to $158 \mathrm{~cm} \mathrm{H}_{2} \mathrm{O}$ among male athletes [3, 6, 16, 17]. However, the authors' own data, $113 \pm 25$ and $141 \pm 29 \mathrm{~cm}$ $\mathrm{H}_{2} \mathrm{O}$, respectively, fit within the scope in question and approximated (women) or exceeded (men) mean interval values. Among female students, PImax values were $68 \%$ of the values for groups of male students, while female athletes measured $80 \%$ of the values for male athletes. 
Table 5. Values of maximal inspiratory mouth pressure (PImax) registered in groups of non-training individuals and groups of athletes from various athletic disciplines (modified after [2])

\begin{tabular}{|c|c|c|c|c|c|c|}
\hline \multirow{2}{*}{ Author } & \multirow{2}{*}{ Group } & \multirow{2}{*}{$\begin{array}{c}\text { Age } \\
\text { (years) }\end{array}$} & \multicolumn{2}{|r|}{ Women } & \multicolumn{2}{|r|}{ Men } \\
\hline & & & N & $P I \max \left(\mathrm{cm} \mathrm{H}_{2} \mathrm{O}\right)$ & N & $P I \max \left(\mathrm{cm} \mathrm{H}_{2} \mathrm{O}\right)$ \\
\hline Chen i Ching-Su [1989] & \multirow{3}{*}{ Non-training individuals } & $16-30$ & 20 & $89 \pm 14$ & 20 & $123 \pm 25$ \\
\hline Fiz et al. [1998] & & $20-29$ & 10 & $90 \pm 26$ & 10 & $135 \pm 33$ \\
\hline Hautmann et al. [2000] & & $18-30$ & 41 & $81 \pm 22$ & 56 & $107 \pm 24$ \\
\hline Authors' study & UPE Students & $19-26$ & 33 & $72 \pm 18$ & 76 & $106 \pm 24$ \\
\hline McConnell et al. [1997] & Moderately trained individuals & $23 \pm 2.8$ & & & 24 & $158 \pm 29$ \\
\hline Fuso et al. [1996] & Elite footballers & $23 \pm 3$ & & & 27 & $114 \pm 32$ \\
\hline Romer et al. [2002] & Cyclists and triathletes & $\begin{array}{l}29.5 \pm 3.3 \mathrm{E} \\
30.3 \pm 2.6 \mathrm{C}\end{array}$ & & & 16 & $\begin{array}{l}102 \pm 6 \mathrm{E} \\
100 \pm 6 \mathrm{C}\end{array}$ \\
\hline Volianitis et al. [2001] & Elite female rowers & $23.8 \pm 3.8$ & 14 & $\begin{array}{c}104 \pm 8 E \\
130 \pm 12 C\end{array}$ & & \\
\hline Klusiewicz et al. [2008] & Elite male rowers & $24.8 \pm 3.2$ & & & 15 & $157 \pm 23$ \\
\hline Klusiewicz [2008] & Athletes engaged in endurance sports & $17-34$ & 30 & $118 \pm 24$ & 35 & $143 \pm 25$ \\
\hline Authors' study & Athletes involved primarily in endurance sports & $17-34$ & 45 & $113 \pm 25$ & 80 & $141 \pm 29$ \\
\hline
\end{tabular}

E - test group, C - control group, UPE - University of Physical Education.

Also noteworthy are the considerable inter-group variations between PImax values, in groups of both male students and male athletes (fig. 2). Minimal values in these groups were almost three times lower than maximum values, and the coefficient of variation was from 21 to $26 \%$, respectively. As Hautmann et al. [10] point out, most publications state that the index in question exhibits high interindividual variability. In the opinion of McConnell et al. [16], individuals with low PImax values exhibit greater susceptibility to respiratory muscle fatigue under exertion. In order to improve the strength (power) of this group of muscles, it is essential to conduct separate, specific training with the use of special equipment that increases inspiratory resistance, as numerous studies have confirmed [3, $4,15,17,18,19]$.

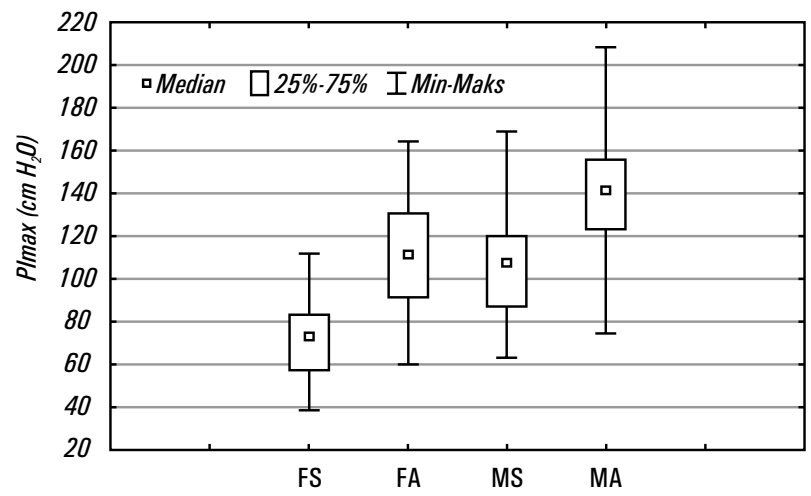

Figure 2. Characterization of maximal inspiratory mouth pressure (PImax) in study groups of non-training and training women and men (FS - female students $n=33, F A-$ female athletes $n=45$, MS - male students $n=76$, MA - male athletes $n=80$ )

A no less important problem is to analyze factors that influence the strength of respiratory muscles. Unfortunately, in the study presented here, no measurements were made of body composition in athletes, and the dependencies asserted between PImax and the analyzed indices (height and body mass, BMI) were not unequivocal (tab. 4). Among female students, a significant positive correlation was observed between PImax and variables characterizing body size (height and body mass) as well as lean body mass. However, these dependencies were not observed for female athletes. In groups of male students and athletes, only athletes exhibited a dependency of PImax on body mass and BMI. This significant positive dependency of BMI among male athletes may suggest the existence of a connection between respiratory muscle strength and overall muscle mass. This is a result of the fact that the male athletes engaging in endurance disciplines generally have low body fat (8-14\%), and the higher BMI values among subjects were most likely attributable to increases in active tissue due to years of training (tab. 1). The abovementioned dependencies indicate that respiratory muscle strength among women and men may be connected to body size. German authors, too [10], in a study of 256 female and 248 male non-athletes, confirmed the existence of strong dependencies between PImax and height, body mass and BMI, as well as forced expiratory volume in 1 second $\left(\mathrm{FEV}_{1}\right)$, peak expiratory flow (PEF), and forced vital capacity (FVC). The strongest correlation occurred in connection with gender and age. In other studies involving groups of non-training individuals numbering in the thousands, the positive predictors of maximal inspiratory pressure (MIP) were male gender, forced vital capacity (FVC), hand grip strength and a high level of lean body mass [20]. However, a negative connection was asserted for age, cigarette smoking, a poor declared state of health and waistline.

In contrast to the above data, McConnel et al. [16], in conducting measurements on moderately trained men, observed no significant correlations between PImax values and $\mathrm{VO}_{2} \max$, height and body mass. Nor were correlations between PImax and test subjects' physical characteristics found to be significant in other studies of healthy, non-training individuals [9]. As the aforementioned authors point out, respiratory muscle strength is conditioned by a multi-factor complex, in contradistinction to the individual dependencies connected with age and somatic features, with consideration given to the strong influence exerted by physical activity.

Contrary to expectations, the correlation coefficients for PImax and training experience observed in the authors' study were not statistically significant, which may indicate that endurance training among highly trained individuals presumably does not influence the subsequent development of respiratory muscle strength, which has also been confirmed in other studies [2]. 


\section{Conclusions}

Measurements taken of indexes for maximal, static mouth pressure (PImax) using apparatus produced by MES Sp. z o.o. were comparable to data in the literature and were confirmed as highly reproducible among healthy, adult women and men. The PImax reference values obtained from the study may be useful as a reference when distinguishing among test subjects for whom separate, specific training of respiratory muscles is advisable. PImax values, regardless of gender, indicate a stronger dependence on body size and lean body mass than on training.

\section{Acknowledgements}

The research was accomplished within the framework of research project of Faculty of Physical Education and Sport in Biała Podlaska, Józef Piłsudski University of Physical Education in Warsaw - DS. 179 - financed by the Ministry of Science and Higher Education in 2013-2015. The tests were conducted in the Regional Centre for Research and Development in Biała Podlaska.

\section{Literature}

1. Sheel A.W. (2002). Respiratory muscle training in healthy individuals. Physiological rationale and implications for exercise performance. Sports Medicine 32, 567-581.

2. Klusiewicz A. (2008). Characteristics of the inspiratory muscle strength in well trained athletes. Biology of Sport 25, 13-22.

3. Klusiewicz A., Borkowski L., Zdanowicz R., Boros P., Wesołowski S. (2008). Inspiratory muscle training in elite rowers. Journal of Sports Medicine and Physical Fitness 48, 279-284.

4. Ozkaplan A., Rhodes E.C. (2004). Exercise induced respiratory muscle fatigue - a review of methodology and recent findings. Biology of Sport 21, 207-230.

5. Wen A.S., Woo M.S., Keens T.G. (1997). How many manoeuvres are required to measure maximal inspiratory pressure accurately? Chest 111, 802-807.

6. Fuso L., di Cosmo V., Nardecchia B., Sammarro S., Pagliari G., Pistelli R. (1996). Maximal inspiratory pressure in elite soccer players. Journal of Sports Medicine and Physical Fitness 36, 67-71.

7. Romer L.M., McConnell A.K. (2004). Inter-test reliability for non-invasive measurements of respiratory muscle function in healthy humans. European Journal Applied Physiology 91, 167-176.

8. Śliwiński P., Walczak J. (2004). Respiratory muscles. In J. Kowalski, A. Koziorowski, L. Radwan (Eds.), An assessment of lung factors in diseases of the respiratory system (pp. 94-128). Warszawa: Wydawnictwo Medyczne Borgis. [in Polish]
9. McConnell A.K., Copestake A.J. (1999). Maximum static respiratory pressures in healthy elderly men and women: issues of reproducibility and interpretation. Respiration 66(3), 252-258.

10. Hautmann H., Hefele S., Schotten K., Huber R.M. (2000). Maximal inspiratory mouth pressures (PImax) in healthy subjects - what is the lower limit of normal? Respiratory Medicine 94(7), 689-693.

11. Coirault C., Chemla D., Lecarpentier Y. (1999). Relaxation of diaphragm muscle. Journal of Applied Physiology 87, 1243-1252.

12. Śliwinski P., Yan S., Gauthier A.P., Macklem P.T. (1996). Function of the diaphragm during exercise. Pneumonologia i Alergologia Polska 64, 577-589.

13. Chen Hsiun-ing, Ching-Su Kuo (1989). Relationship between respiratory muscle function and age, sex, and other factors. Journal of Applied Physiology 66, 943-948.

14. Fiz J.A., Romero P., Gomez R., Hernandez M.C., Ruiz J., Izquierdo J. et al. (1998). Indices of respiratory muscle endurance in healthy subjects. Respiration 65, 21-27.

15. Volianitis S., McConnell A.K., Koutedakis Y., Mcnaughton L., Backx K., Jones D.A. (2001). Inspiratory muscle training improves rowing performance. Medicine and Science in Sports and Exercise 33, 803-809.

16. McConnell A.K., Caine M.P., Sharpe G.R. (1997). Inspiratory muscle fatigue following running to volitional fatigue: The influence of baseline strength. International Journal of Sports Medicine 18, 169-173.

17. Romer L.M., McConnell A.K., Jones D.A. (2002). Effects of inspiratory muscle training on time-trial performance in trained cyclists. Journal of Sports Sciences 20, 547-562.

18. Lomax M., Grant I., Corbett J. (2011). Inspiratory muscle warm-up and inspiratory muscle training: separate and combined effects on intermittent running to exhaustion. Journal of Sports Sciences 29(6), 563-569.

19. Riganas C.S., Vrabas I.S., Christoulas K., Mandroukas K. (2008). Specific inspiratory muscle training does not improve performance or $\mathrm{VO}_{2}$ max level in well trained rowers. Journal of Sports Medicine and Physical Fitness 48(3), 285292.

20. Enright P.L., Kronmal R.A., Manolio T.A., Schenker M.B., Hyatt R.E. (1994). Respiratory muscle strength in the elderly. Correlates and reference values. American Journal of Respiratory and Critical Care Medicine 149(2 Pt 1), 430-438.

Submitted: March 7, 2014

Accepted: May 5, 2014 